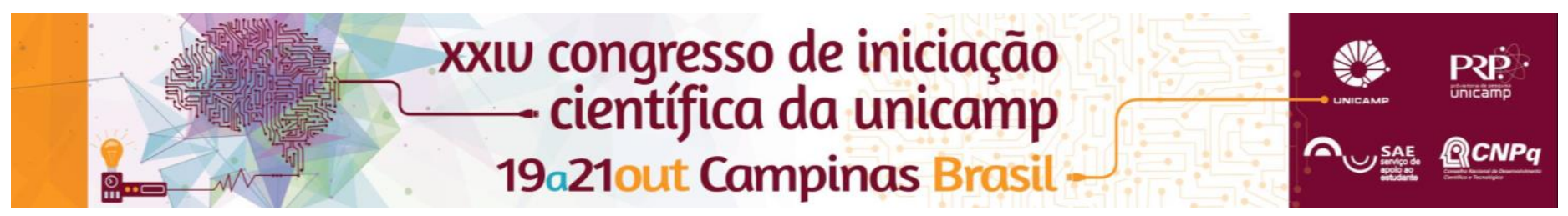

\title{
Análise da existência de portas de entrada e os desafios do seguimento, em relação ao usuário da Saúde Mental na Atenção Básica.
}

\author{
Waisbich, Susan*, Onocko Campos, Rosana.
}

\section{Resumo}

Pesquisa qualitativa, em que entrevistas semi-estruturadas foram feitas com 05 usuários da saúde mental, portadores de transtornos graves, para se entender como foi o acesso e seguimento na Atenção Básica, buscando-se valorizar o ponto de vista do usuário, algo pouco explorado nas pesquisas avaliativas. O processo de seleção desses usuários se deu através do "snowball technique", utilizando-se um questionário da Mc Guill traduzido para a realidade brasileira como base da entrevista. O acesso a experiência dos usuários permite uma reflexão sobre as condições dos serviços que poderiam favorecer 0 acesso e o recovery.

\section{Palavras-chave:}

Pesquisa qualitativa, acesso do usuário, "recovery", experiência do adoecimento, pesquisa avaliativa.

\section{Introdução}

Há falta de estudos no que tange ao seguimento de usuários da Saúde Mental e à avaliação de sua evolução. Um fator de dificuldade para desenvolver esses estudos seria o estigma, que os usuários sofrem, o que os levaria a evitar se expor e demandar assistência em serviços não especializados, como os da Atenção Primária à Saúde.

"Recovery"1 é um conceito cunhado pelo movimento anglo-saxão de usuários que destaca o processo de recuperação e melhora no entendimento dos próprios usuários, bem como se ocorre ou não o empoderamento desses usuários e se eles sentem estar tendo uma vida significativa, independente da remissão de sintomas, sendo um conceito recente no contexto da Saúde Mental brasileira.

Este estudo se propôs avaliar a percepção de recovery de usuários de saúde mental que não estão vinculados a serviços especializados.

\section{Metodologia:}

Através do método da "SNOWBALL TECHNIQUE", um usuário da saúde mental não vinculado a nenhum serviço especializado e que se considera em recovery foi o entrevistado inicial e este indicou mais um usuário e assim por diante até completar cinco usuários com as mesmas características, quantidade total de pessoas que deveriam ser entrevistadas. As entrevistas foram semiestruturadas, baseadas em questionário da Universidade Mcghill traduzido e adaptado para a realidade brasileira2.

As entrevistas foram audiogravadas e transcritas em sua íntegra, sendo o projeto submetido ao Comitê de Ética e aprovado sob o número da CAAE 47824215.8.0000.5404.

\section{Resultados e Discussão}

A partir dos temas que apareceram nas entrevistas, seis grupos de temas foram discutidos: o olhar do usuário sobre a atenção básica em termos de saúde mental, a necessidade de mudanças em relação ao acolhimento, a diferença de visão entre 0 que 0 DOI: 10.19146/pibic-2016-51217 trabalhador da saúde mental aplicou e como o usuário a recebeu ("empoderamento real e virtual"), o estigma em relação à saúde mental, a necessidade de momentos para se colocar e a visão do pesquisador em relação às entrevistas.

Dar voz ao usuário acabou sendo uma forma de "empowerment"3 e o manejo da entrevista foi essencial para manter os usuários abertos à entrevista, que variou muito de tempo de conversa, mas teve sempre grande intensidade.

\section{Conclusões}

Diferentemente dos achados de outros estudos ${ }^{4}$, o CAPS foi criticado quanto à forma de ação com os usuários, assim como em relação à medicalização. Além disso, os usuários relataram a estigmatização a que sofreram ao passarem em consulta na Atenção Básica, por possuírem um transtorno mental. Diante desse contexto, observa-se a importância de se compreender a visão do usuário para que as políticas públicas e a clínica relacionada à Saúde Mental possam ser cada vez mais aperfeiçoadas.

\section{Agradecimentos}

Ao grupo interfaces Saúde Mental-Saúde Coletiva, inspiração para o projeto; à minha família que tanto discute Saúde Mental e, principalmente, aos usuários, queridos professores.

1 JACOBSON, Nora; CURTIS, Laurie. Recovery as policy in mental health services: Strategies emerging from the states. Psychiatric Rehabilitation Journal, v. 23, n. 4, p. 333-341, 2000.

2. http://www.mcgill.ca/tcpsych/files/tcpsych/mini_portugueuse.pdf - modelo para a entrevista semi-estruturada, acessado em 15/04/15.

3. JORM, Anthony F. Mental health literacy: empowering the community to take action for better mental health. American Psychologist, v. 67, n. 3, p. 231, 2012.

4. DE LIMA, Luciana Togni; SURJUS, Silva; CAMPOS, Rosana Onocko. A avaliação dos usuários sobre os Centros de Atenção Psicossocial (CAPS) de Campinas, SP. Revista Latinoamericana de Psicopatologia Fundamental, v. 14, n. 1, p. 122-133, 2011. 